\title{
IMPLEMENTASI METODE MARKER BASED TRACKING PADA APLIKASI BANGUN RUANG BERBASIS AUGMENTED REALITY
}

\author{
Bagus Satria ${ }^{1)}$, Prihandoko ${ }^{2)}$ \\ ${ }^{1,2}$ Teknik Informatika, Fakultas Pascasarjana Teknik Informatika, Universitas AMIKOM Yogyakarta \\ ${ }^{1,2}$ Jl. Ring Road Utara, Condongcatur, Kec. Depok, Kabupaten Sleman, Daerah Istimewa Yogyakarta 55281 \\ E-mail : bagoezsatria182@.com ${ }^{1)}$,pri@staff.gunadarma.ac.id ${ }^{2)}$
}

\begin{abstract}
ABSTRAK
Saat ini media yang digunakan dalam pembelajaran bangun ruang hanya berupa papan tulis ataupun buku cetak sehingga sisi bagian dalam dan belakang dari bagian tersebut tidak terlihat. Biasanya guru menggunakan alat peraga untuk memvisualisasikan bagun ruang tersebut, namun siswa harus bergantian untuk bisa melihat secara dekat bangun ruang tersebut, karena tidak memungkinkan tiap siswa mendapat semua jenis alat peraga dengan banyaknya jenis bangun ruang. Untuk memenuhi tuntutan tersebut dibutuhkan aplikasi yang dapat menampilkan bentuk bangun ruang 3 dimensi agar siswa dapat memahami bentuk dari masing-masing bangun ruang. Aplikasi Bangun Ruang berbasis augmented reality adalah aplikasi multimedia yang menggabungkan data grafis bentuk bangun ruang 3 dimensi dengan media buku. Penelitian ini akan mengimplementasikan metode marker based tracking pada aplikasi pembalajaran bangun ruang berbasis augmented reality. Dengan adanya perpaduan teknologi modern yaitu visualisasi 3D dalam hal ini penulis menggunakan Augmented Reality, maka bangun ruang yang akan diajarkan guru kepada siswa akan terasa lebih menarik dan membuat siswa dapat memahami bentuk dan rumus-rumus dari bangun ruang tersebut.
\end{abstract}

Kata Kunci: augmented reality, marker based tracking

\section{PENDAHULUAN}

Bangun ruang adalah salah satu materi yang dipelajari dalam matematika. Bangun ruang merupakan bangun tiga dimensi yang memiliki ruang dan dibatasi oleh sisi-sisi. Setiap jenis dari bangun ruang memiliki bentuk, luas dan volume masing-masing (Djumanta 2008).

Saat ini media yang digunakan dalam pembelajaran bangun ruang hanya berupa papan tulis ataupun buku cetak sehingga sisi bagian dalam dan belakang dari bagian tersebut tidak terlihat. Biasanya guru menggunakan alat peraga untuk memvisualisasikan bagun ruang tersebut, namun siswa harus bergantian untuk bisa melihat secara dekat bangun ruang tersebut, karena tidak memungkinkan tiap siswa mendapat semua jenis alat peraga dengan banyaknya jenis bangun ruang. Tempat penyimpanan alat peraga dan banyaknya jenis alat peraga yang harus dibawa kedalam kelas juga menjadi kendala tersendiri.

Untuk memenuhi tuntutan tersebut sejalan dengan perkembangan ilmu pengetahuan dan teknologi, khususnya dalam bidang pendidikan, penggunaan media pembelajaran menjadi semakin beragam dan interaktif, salah satunya yang sedang marak saat ini adalah dengan memanfaatkan teknologi Augmented Reality (AR).

Augmented Reality (AR) adalah bidang penelitian komputer yang menggabungkan data grafis 3D dengan dunia nyata atau dengan kata lain realita yang ditambahkan ke suatu media . Media ini dapat berupa kertas, sebuah marker atau penanda melalui perangkatperangkat input tertentu. Teknologi ini tidak sepenuhnya menggantikan sebuah realitas, tapi menambahkan (augment) sebuah atau beberapa benda-benda maya dalam bentuk 2 atau 3 dimensi kedalam lungkungan nyata 3 dimensi dan ditampilkan secara realtime (Ronald T.Azuma, 2014).

Augmented Reality berdasarkan metode pelacakannya (tracking) terbagi atas dua, yaitu marker based tracking dan markerless tracking. Marker based tracking menggunakan penanda/marker dengan bentuk hitam dan putih persegi dengan batas hitam tebal dan latar belakang putih. Sedangkan metode Markerless tracking penanda/marker dapat dibuat dengan bentuk apapun.

Pada penelitian ini akan diimplementasikan metode marker based tracking pada Aplikasi Bangun Ruang berbasis augmented reality. Dengan penelitian ini diharapkan Aplikasi Bangun Ruang berbasis augmented reality dengan metode marker based tracking ini dapat menampilkan objek bangun ruang 3 dimensi sehingga dapat menambahkan minat dan pemahaman pelajar yang sedang mempelajarinya.

\section{RUANG LINGKUP PENELITIAN}

Permasalahan difokuskan pada: Bagaimana mengimentasikan metode marker based tracking pada Aplikasi Bangun Ruang berbasis augmented reality.

\section{BAHAN DAN METODE}

\subsection{Bangun Ruang}

Bangun ruang menurut Djumanta (2008) disebut juga bangun tiga dimensi. Bangun ruang merupakan sebuah bangun yang memiliki ruang yang dibatasi oleh beberapa sisi. Jumlah dan model yang membatasi bangun tersebut menentukan nama dan bentuk bangun tersebut, misalnya 
bangun yang dibatasi oleh 6 sisi yang sama ukuran dan bentuknya disebut kubus, bangun yang dibatasi oleh 6 sisi yang mempunyai ukuran panjang dan lebar/persegi panjang disebut balok dan prisma, bangun yang dibatasi oleh sisi lengkung dan dua buah lingkaran disebut Tabung. Jumlah serta model sisi yang dimiliki oleh sebuah bangun tertentu merupakan salah satu sifat bangun ruang tersebut. Jadi, sifat suatu bangun ruang ditentukan oleh jumlah sisi, model sisi, dan lain-lain.

\subsection{Augmented Reality}

Menurut Ronald T.Azuma (2014) mendefinisikan Augmented reality sebagai penggabungan benda benda nyata dan maya di lingkungan nyata, berjalan secara interaktif dalam waktu nyata dan terdapat integrasi dan maya dimungkinkan dengan teknologi tampilan yang sesuai, interaktivitas dimungkinkan melalui perangkatperangkat input tertentu, dan integrasi yang baik memerlukan penjelasan yang efektif.

Cara kerja augmented reality dalam menambahkan objek virtual ke lingkungan nyata adalah sebagai berikut :

1. Perangkat input menangkap video dan mengirimkannya ke prosesor.

2. Perangkat lunak didalam prosesor mengolah video dan mencari suatu pola.

3. Perangkat lunak menghitung posisi pola untuk mengetahui dimana objek virtual akan diletakkan.

4. Perangkat lunak mengidentifikasi pola dan mencocokannya dengan informasi yang dimiliki perangkat lunak.

5. Objek virtual akan ditambahkan sesuai dengan hasil pencocokan informasi dan diletakkan pada posisi yang telah dihitung sebelumnya.

6. Objek virtual akan ditampilkan melalui perangkat tampilan.

Cara kerja ini augmented reality dapat dilihat pada gambar 1

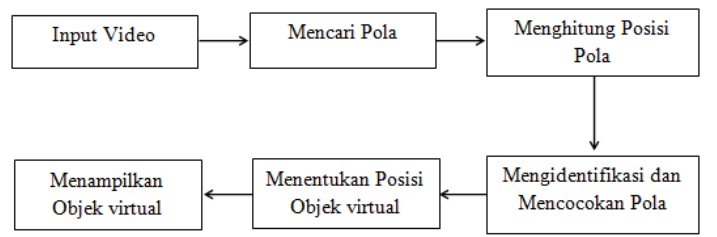

Gambar 1. Diagram sistem cara kerja Augmented Reality

\subsection{Marker Based Tracking}

Marker based tracking merupakan metode augmented reality yang mengenali marker dan mengidentifikasi pola dari marker tersebut untuk menambahkan suatu objek virtual ke lingkungan nyata (Chari, 2008). Marker merupakan ilustrasi persegi hitam dan putih dengan sisi hitam tebal, pola hitam ditengah persegi dan latar belakang putih. Contoh marker dapat dilihat pada gambar 2 .

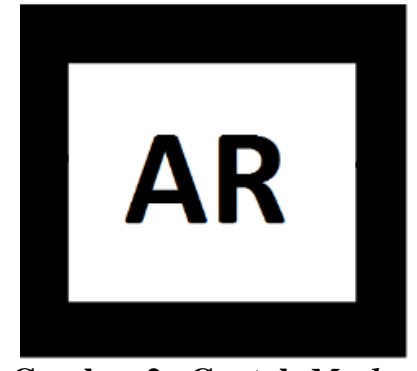

Titik koordinat virtual pada marker berfungsi untuk menentukan posisi dari objek virtual yang akan ditambahkan pada lingkungan nyata. Posisi dari objek virtual akan terletak tegak lurus dengan marker. Objek virtual akan berdiri segaris dengan sumbu $\mathrm{Z}$ serta tegak lurus terhadap sumbu X (kanan atau kiri) dan sumbu $\mathrm{Y}$ (depan atau belakang) dari koordinat virtual marker. Ilustrasi dari titik koordinat virtual marker dapat dilihat pada gambar 3 .

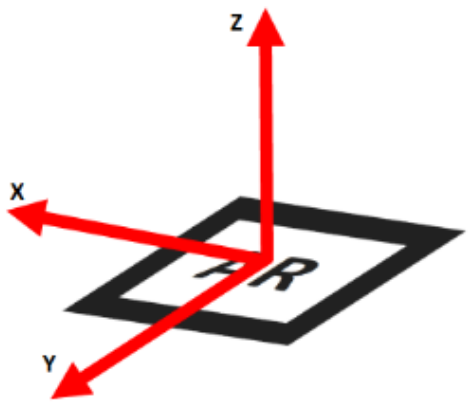

Gambar 3. Titik Koordinat Virtual pada Marker

Proses tracking dimulai dari tahap inputImage. Tahap ini merupakan tahap dimana prosesor mengolah secara realtimeframe per frame dari video hasil tangkapan perangkap tangkapan. Tahap berikutnya adalah thresholding image, pada tahap ini tiap frame video mengalami proses thresholding sehingga menghasilkan gambar hitam putih. Tahap ini bertujuan untuk mengenali bentuk segi empat dan pola marker dari video yang telah ditangkap (Christoper, 2012).

Proses tracking adalah marker detection atau pendeteksian marker, pada tahap interdiri dari empat proses, yaitu : contours extraction, corner detection, pattern normalization dan template matching. Proses contours extraction dan corner detection dapat dilihat pada gambar 4

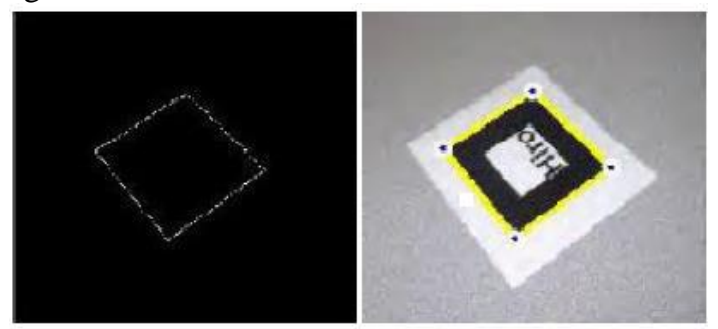

Gambar 4. Contours Extraction dan Corner Detectio 
Proses contours extraction dan corner detection memanfaatkan gambar hitam putih yang didapat pada tahap kedua untuk mendapatkan koordinat dari empat sisi dan empat titik sudut marker (Christoper, 2012) terdapat pada gambar 5

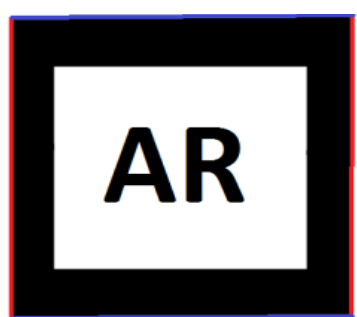

\section{Gambar 5. Dua garis paralel pada Marker}

Dua proses berikutnya pada tahap markerdetection adalah pattern normalizatiion dan template matching dapat dilihat pada gambar 6. Proses pattern normalization bertujuan menormalisasikan bentuk marker sehingga proses template matching dapat dilakukan dengan tepat.

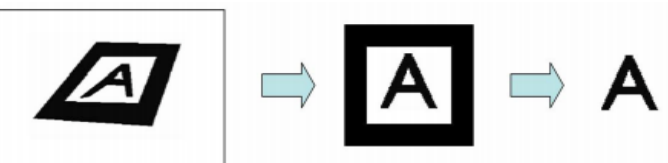

\section{Gambar 6. Pattern Normalization dan Template Matching}

Tahap terakhir adalah tahap pose and position estimation. Tahap ini yang bertanggung jawab dalam peletakan objek virtual di atas marker. Pada tahap ini hubungan antar tiga koordinat memegang peranan penting, yaitu koordinat dari perangkat tampilan (observed screen coordinates) (Christoper, 2012). Sistem koordinat dapat dilihat pada gambar 7.

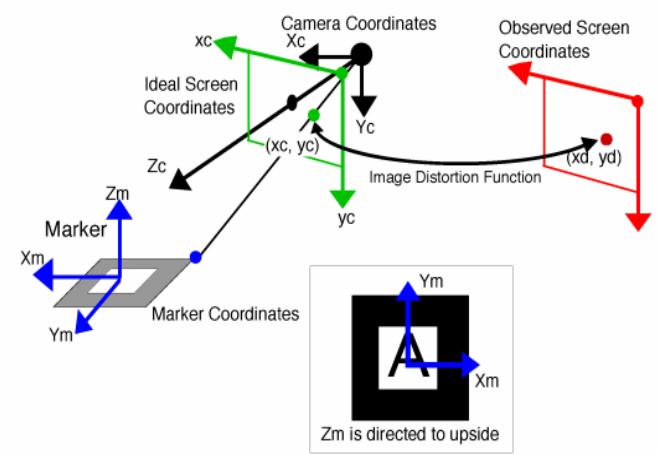

Gambar 7. Sistem Koordinat

Pada tahap ini dilakukan proses transformasi yang dibutuhkan untuk mendapatkan posisi kamera relatif terhadap marker dalam koordinat dari penangkapan video.

\subsection{Metode Pengumpulan Data}

Data yang dikumpulkan terdiri atas data sekunder dan data primer. Data primer berasal dari lokasi pengkajian secara langsung, yang dilakukan melalui wawancara maupun kuisioner di SMP Negeri 1 Anggana, Kutai Kartanegara. Sedangkan data sekunder diperoleh dengan mempelajari studi literatur yang berupa aturan-aturan tertulis atau dokumen yang ada kaitannya judul penelitian. Selain itu data juga di dapat melalui observasi atau pengamatan langsung di kelas saat proses belajarmengajar.

\subsection{Alur Penelitian}

Langkah-langkah alur penelitian tertera dalam kerangka penelitian pada gambar 8 berikut:

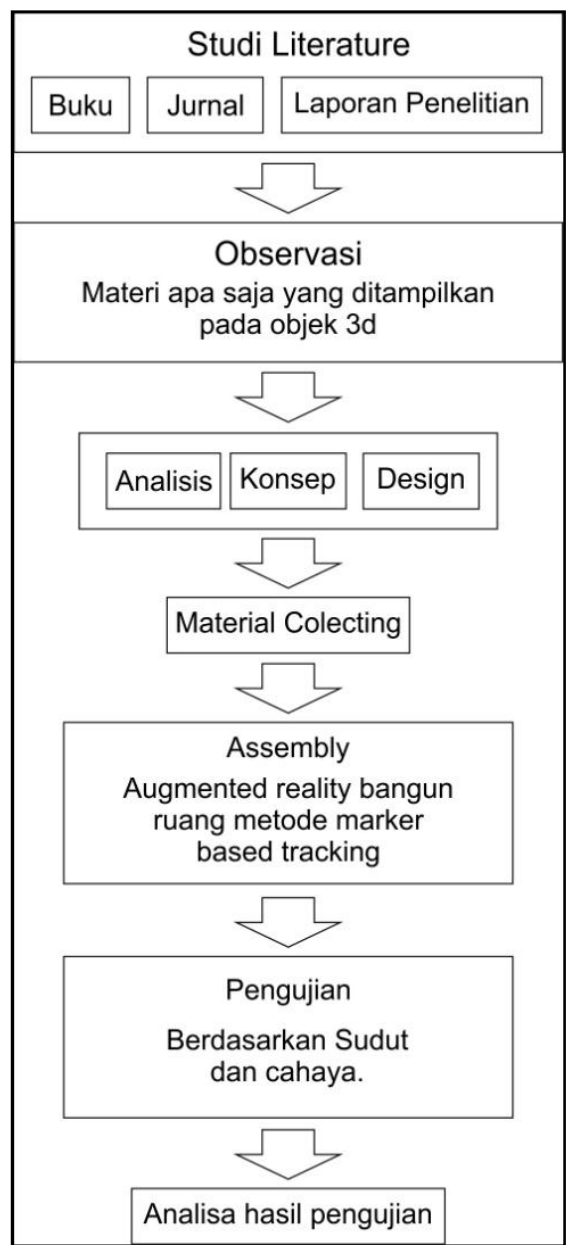

Gambar 8. Kerangka penelitian

1. Studi literature, mencari dan mempelajari literature dari buku, jurnal, serta penelitian sebelumnya yang berkaitan dengan metode marker based tracking augmented reality.

2. Melakukan observasi materi apa saja yang akan ditampilkan pada aplikasi bangun ruang metode marker based tracking augmented reality.

3. Proses pendekatan pengembangan media pembelajaran dengan metode pengembangan sistem multimedia, mulai dari desain sampai material collecting.

4. Tahap assembly dibuat aplikasi pembelajaran bangun ruang berbasis augmented realitydengan metode marker based tracking. 
5. Melakukan pengujian aplikasi berdasarkan jarak dan cahaya.

6. Menganalisa hasil pengujian untuk mengetahui apakah aplikasi telah berjalan dengan baik dan apa saja keterbatasan dari aplikasi ini.

\section{RANCANGAN APLIKASI}

Berikut disajikan rancangan aplikasi yang dibangun :

\subsection{Rancangan Marker dalam Pembelajaran bangun} ruang berbasis Augmented Reality

Marker/penanda yang digunakan dalam metode marker based tracking merupakan ilustrasi persegi hitam dan putih dengan sisi hitam tebal, pola hitam ditengah persegi dan latar belakang putih. Salah satu marker yang digunakan pada aplikasi ini yaitu marker prisma seperti terlihat pada gambar 9 .

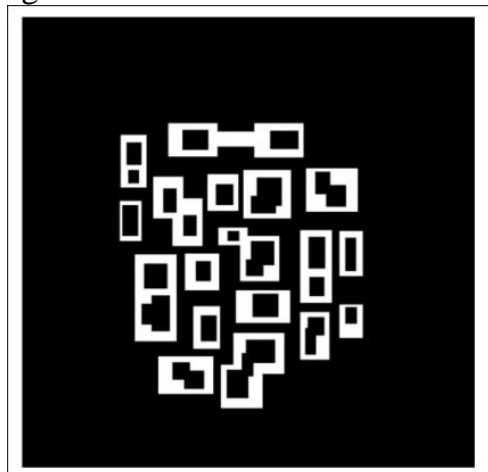

Gambar 9. Marker prisma

\subsection{Rancangan Objek 3 Dimensi dala Pembelajaran} bangun ruang berbasis Augmented Reality

Objek 3 dimensi bangun ruang memiliki tampilan objek padat, objek terbelah / rangka objek, elemenelemen dari objek, dan rumus-rumus yang berlaku pada objek tersebut. Objek padat merupakan tampilan dari bentuk objek bangun ruang secara utuh. Objek terbelah atau rangka objek merupakan tampilan untuk menampilkan bagian dalam objek dan diberi keterangan elemen-elemen yang terdapat pada objek tersebut seperti tinggi, panjang, lebar, sisi, jari-jari, dan alas. Rumusrumus yang berlaku pada objek tesebut ditampilkan dibagian atas, rumus-rumus yang ditampilkan seperti luas selimut, luas permukaan dan volume. Seperti yang terlihat pada gambar 9

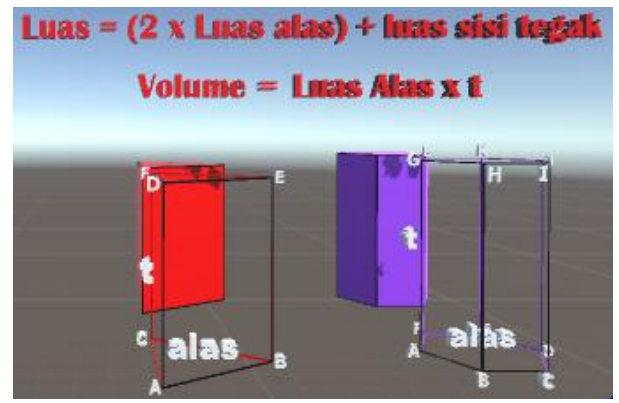

Gambar 9. Obek 3 dimensi

\section{IMPLEMENTASI}

Hasil implementasi berdasarkan analisis dan perancangan adalah sebagai berikut :

\subsection{Tampilan objek 3 dimensi pada aplikasi bangun ruang berbasis Augmented Reality}

Salah satu objek 3 dimensi bangun ruang yaitu Prisma 3 dimensi dengan tampilan objek prisma padat, rangka prisma dan rumus prisma. Ada dua jenis prisma yang ditampilkan yaitu prisma segitiga dan prisma segienam. Saat AR kamera diarahkan pada marker prisma maka objek 3 dimensi prisma akan tampil seperti yang terlihat pada gambar 10 dibawah ini.

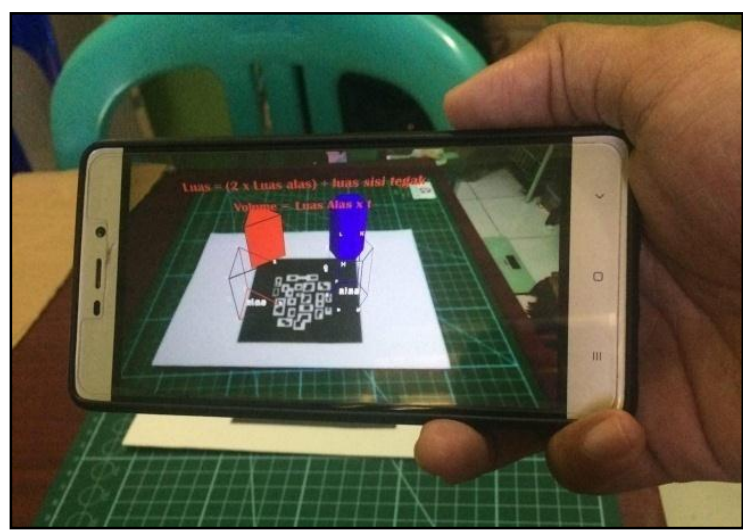

Gambar 10. Tampilan objek 3 dimensi pada aplikasi bangun ruang berbasis Augmented Reality

\subsection{Keterbatasan Aplikasi Bangun Ruang berbasis Augmented Reality}

Aplikasi Bangun Ruang berbasis Augmented Reality memiliki beberapa keterbatasan dalam hal penggunaannya yang dipengaruhi oleh beberapa factor, yaitu:

1. Oklusi

Objek virtual hanya akan muncul ketika marker ditangkap kamera. Hal ini membatasi ukuran atau gerakan dari objek virtual. Ini juga berarti bahwa jika pengguna menutupi pola yang ada pada marker dengan tangan mereka atau benda lain, objek virtual akan menghilang.

2. Jarak

Jarak juga menjadi masalah dalam pelacakan optik, ketika marker bergerak menjauhi kamera, mereka menempati lebih sedikit piksel pada layar kamera, dan mungkin tidak cukup detail untuk dapat dengan benar mengidentifikasi pola pada marker.

Dengan menggunakan salah satu marker dari Aplikasi Bangun Ruang berbasis Augmented Reality yaitu marker prisma dengan ukuran yang berbeda. Hasil ini didapatkan dengan menggerakkan marker menjauhi kamera sampai pada jarak tertentu objek virtual 3 dimensi yang berada diatas marker menghilang. Seperti yang terlihat pada tabel 1 . 
Tabel 1. Jarak Kamera - Marker

\begin{tabular}{|l|c|}
\hline Marker & $\begin{array}{c}\text { Jarak Kamera } \\
\text { Marker }\end{array}$ \\
\hline Ukuran $(\mathrm{cm})$ & Terjauh $(\mathrm{cm})$ \\
\hline $4 \times 4$ & 45 \\
\hline $6 \times 6$ & 61 \\
\hline $8 \times 8$ & 78 \\
\hline $12 \times 12$ & 117 \\
\hline $16 \times 16$ & 159 \\
\hline
\end{tabular}

3. Cahaya

Faktor cahaya yang dapat ditangkap oleh lensa kamera juga berperan penting karena apabila menampilakan marker ke kamera pada saat kondisi cahaya gelap/kurang terang, ataupun kondisi cahaya sangat terang/silau maka kamera akan susah dalam mengenali marker dan objek virtual tidak dapat tampil.

\section{KESIMPULAN}

Berdasarkan uraian dari masing- masing bab dan hasil pembahasan maka dapat disimpulkan bahwa pembuatan pembelajaran bangun ruang berbasis augmented reality dengan metode marker based tracking sebagai berikut :

1. Bangun Ruang yang akan ditampilkan pada Aplikasi Bangun Ruang berbasis augmented reality dengan metode marker based tracking ini adalah pelajaran bangun ruang untuk tingkat SMP.

2. Aplikasi Bangun Ruang berbasis augmented reality dengan metode marker based tracking ini hanya dapat dijalankan dengan menggunakan Samrtphone dengan sistem operasi Android yang telah memiliki fasilitas kamera.

3. Metode yang digunakan adalah Marker Based Tracking.

4. Jarak dan cahaya berpengaruh pada keberhasilan kamera AR mengenali marker dan menampilkan objek virtual 3 dimensi.

\section{SARAN}

Berdasarkan hasil dari penelitian ini akan beberapa saran, yaitu sebagai berikut :

1. Menambahkan fitur animasi bergerak 3 dimensi yang lebih menarik agar siswa lebih tertarik belajar melalui aplikasi ini.

2. Dapat menggunakan metode lain seperti markerless tracking.

\section{DAFTAR PUSTAKA}

Apriyan, M. E., Huda, M., Prasetyaningsih, S., Analisis Penggunaan Marker Tracking Pada Augmented Reality Huruf Hijaiyah, Jurnal Infotel, Vol. 8 No.1, Mei 2016.

Azuma, R.T. 2014. A Survey Of Augmented Reality : Presence Teleoperators and Virtual Environments Hughes Research Laboratories.
Buchori, A., Setyosari, P., Dasna, I. W.,Ulfa, S., 2017, Mobile Augmented Reality Media Design with Waterfall Model for Learning Geometry in College, International Journal of Applied Engineering Research, Vol.12, No.13, 2017.

Chari, Singh J.M. dan Narayanan P.J. 2008. Augmented reality using over-segmentation. Center for Visual Information Technology, International Institute of Information Technology.

Christoper. 2012, Markerless Augmented Reality for Panoramic Sequences : School of Information Technology and Engineering Faculty of Engineering University of Ottawa Canada.

Dedynggego, Mohammad, Affan, M., Perancangan Media Pembelajaran Interaktif 3D Tata Surya Menggunakan Teknologi Augmented Reality Untuk Siswa Kelas 6 Sekolah Dasar Sangira, Jurnal Elektronik Sistem Informasi Dan Komputer, Vol.1, No.2, Desember 2015

Djumanta, Wahyudin. 2008, Belajar Matematika Aktif dan Menyenangkan Untuk SMP/MTS Kelas IX. Departemen Pendidikan Nasional.

Setyawan, R. A., Dzikri, A., Analisis Penggunaan Metode Marker Tracking Pada Augmented Reality Alat Music Tradisional Jawa Tengah, Jurnal SIMETRIS, Vol.7 No.1, April 2016, ISSN: 2252-4983

Wiradarma, I. G. G. R.,, Darmawiguna, I. G. M., Sunarya, I. M. G., Pengembangan Aplikasi Markerless Augmented Reality Balinese Story "I Gede Basur", Jurnal Nasional Pendidikan Teknik Informatika, Volume 6, Nomor 1, Maret 2017. 